\title{
One-dimensional horizontal infiltration experiment for determining permeability coefficient of loamy sand
}

\author{
HU Shunjun ${ }^{1 *}$, ZHU Hai ${ }^{1,2}$, CHEN Yongbao ${ }^{1,3}$ \\ ${ }^{1}$ State Key Laboratory of Desert and Oasis Ecology, Xinjiang Institute of Ecology and Geography, Chinese Academy of \\ Sciences, Urumqi 830011, China; \\ ${ }^{2}$ University of Chinese Academy of Sciences, Beijing 100049, China; \\ ${ }^{3}$ Central South Institute of Metallurgical Geology, Yichang 443003, China
}

\begin{abstract}
A knowledge of soil permeability is essential to evaluate hydrologic characteristics of soil, such as water storage and water movement, and soil permeability coefficient is an important parameter that reflects soil permeability. In order to confirm the acceptability of the one-dimensional horizontal infiltration method (one-D method) for simultaneously determining both the saturated and unsaturated permeability coefficients of loamy sand, we first measured the cumulative infiltration and the wetting front distance under various infiltration heads through a series of one-dimensional horizontal infiltration experiments, and then analyzed the relationships of the cumulative horizontal infiltration with the wetting front distance and the square root of infiltration time. We finally compared the permeability results from Gardner model based on the one-D method with the results from other two commonly-used methods (i.e., constant head method and van Genuchten model) to evaluate the acceptability and applicability of the one-D method. The results showed that there was a robust linear relationship between the cumulative horizontal infiltration and the wetting front distance, suggesting that it is more appropriate to take the soil moisture content after infiltration in the entire wetted zone as the average soil moisture content than as the saturated soil moisture content. The results also showed that there was a robust linear relationship between the cumulative horizontal infiltration and the square root of infiltration time, suggesting that the Philip infiltration formula can better reflect the characteristics of cumulative horizontal infiltration under different infiltration heads. The following two facts indicate that it is feasible to use the one-D method for simultaneously determining the saturated and unsaturated permeability coefficients of loamy sand. First, the saturated permeability coefficient (prescribed in the Gardner model) of loamy sand obtained from the one-D method well agreed with the value obtained from the constant head method. Second, the relationship of unsaturated permeability coefficient with soil water suction for loamy sand calculated using Gardner model based on the one-D method was nearly identical with the same relationship calculated using van Genuchten model.
\end{abstract}

Keywords: permeability coefficient; one-dimensional horizontal infiltration; cumulative horizontal infiltration; wetting front distance; Philip infiltration formula; Gardner model

Citation: HU Shunjun, ZHU Hai, CHEN Yongbao. 2017. One-dimensional horizontal infiltration experiment for determining permeability coefficient of loamy sand. Journal of Arid Land, 9(1): 27-37. doi: 10.1007/s40333-016-0062-3

\section{Introduction}

Soil permeability, an important physical property of soil, is influenced by the shape, size, and continuity of the pore spaces (Scherer et al., 1996; Zhang et al., 2013). A knowledge of soil permeability is essential to evaluate soil hydrologic characteristics, such as water storage and

*Corresponding author: HU Shunjun (E-mail: xjhushunjun@aliyun.com)

Received 2016-01-13; revised 2016-06-19; accepted 2016-07-25

(C) Xinjiang Institute of Ecology and Geography, Chinese Academy of Sciences, Science Press and Springer-Verlag Berlin Heidelberg 2017 
water movement (Schiff and Dreibelbis, 1949). Soil permeability coefficient (or hydraulic conductivity) including saturated and unsaturated permeability coefficients is an important parameter that reflects soil hydrologic characteristics (Daliri, 2011; Wang and Tong, 2014).

Soil permeability coefficient can be determined by three groups of methods: theoretical, laboratory and field methods (Klute and Dirksen, 1986; Fredlund and Rahardjo, 1993; Radcliffe and Rasmussen, 2002; Lal and Shukla, 2004; Lu and Likos, 2012; Ganjidoost et al., 2015), but all of those methods have advantages and disadvantages (Wang and Tong, 2014; Ganjidoost et al., 2015). Theoretical methods are based on water viscosity and soil porosity, and the water flow in soil is assumed to be viscous flow rather than turbulent flow. Thus, this group of methods are often not reliable due to the nonuniformities of soil grain size distributions and particle shapes (Fredlund and Rahardjo, 1993). Laboratory methods often fail to accurately simulate field conditions because of sampling restriction (e.g., limited amount, limited size, disturbance, and heterogeneity) (Fredlund and Rahardjo, 1993). In contrast, field methods can objectively reflect the actual situation of soil permeability with little disturbance. However, field methods still have shortcomings, such as high testing complexity, laborious workload, long testing periods and high expenses. Therefore, it is necessary to develop a relatively simple and yet widely applicable method to determine both the saturated and unsaturated permeability coefficients from simple experiments or easily obtainable parameters.

One-dimensional horizontal infiltration experiment was widely used to estimate soil water movement parameters (Wang et al., 1990; Shao et al., 1998; Wang et al., 2002; Shabani and Sepaskhah, 2009). Yang and Lei (1991) proposed a simple method to determine soil permeability coefficients under different infiltration heads using the one-dimensional horizontal infiltration method (one-D method). Compared with other methods that can only determine either the saturated permeability coefficient or unsaturated permeability coefficient, this method can simultaneously determine both the saturated permeability coefficient and unsaturated permeability coefficient (Yang and Lei, 1991; Su, 2000). This study aimed at confirming the acceptability and applicability of the one-D method for determining the saturated and unsaturated permeability coefficients. The saturated permeability coefficient and the pore size distribution parameter prescribed in the Gardner model (Gardner, 1958) for loamy sand were determined using the one-D method and thus the unsaturated permeability coefficient was subsequently obtained from the Gardner model. Specifically, we measured the cumulative horizontal infiltration and the wetting front distance corresponding to different infiltration times under various infiltration heads through a series of one-dimensional horizontal infiltration experiments. We then analyzed the relationships of the cumulative horizontal infiltration with the wetting front distance and the square root of infiltration time. We finally compared the permeability results calculated using Gardner model based on the one-D method with those calculated using the other two commonly-used methods to further confirm the acceptability and applicability of the one-D method. The other two commonly-used methods were the constant head method (Jury et al., 1991; Hillel, 1998) and the van Genuchten model (van Genuchten, 1980).

\section{Theoretical analysis}

\subsection{Saturated permeability coefficient}

Darcy's equation, which describes the one-dimensional horizontal unsaturated flow of water in soils, is as follows (Yang and Lei, 1991):

$$
q=-\frac{\partial \varphi}{\partial x}
$$

Where, $q$ is the soil moisture flux $(\mathrm{cm} / \mathrm{min}) ; \varphi$ is the velocity potential $\left(\mathrm{cm}^{2} / \mathrm{min}\right)$; and $x$ is the horizontal coordinate $(\mathrm{cm})$ with $x=0$ at the entry surface.

By employing the Kirchhoff transformation (Klute, 1952; Gardner, 1958; Philip et al., 1989; Houseworth and Leej, 2009), $\varphi$ can be obtained from Equation 2. 


$$
\varphi=\int_{\Psi_{i}}^{\Psi} K(\Psi) d \Psi .
$$

Where, $\Psi$ is the soil water pressure potential $(\mathrm{cm})$, and $\Psi$ is the soil pressure potential $\Psi_{p}$ when $\Psi>0$, while $\Psi$ is the soil matric potential $\Psi_{m}$ when $\Psi<0 ; \Psi_{i}$ is the initial soil matric potential before infiltration $(\mathrm{cm})$ and $K(\Psi)$ the unsaturated permeability coefficient $(\mathrm{cm} / \mathrm{min})$.

The relationship between $K(\Psi)$ and $\Psi$ is shown in Figure 1 (Elrick et al., 1989; Ankeny et al., 1991; Elrick and Reunolds, 1992). $\varphi$ in Figure 1 represents the area enclosed by the curve $K(\Psi)$ from $\Psi_{i}$ to $\Psi$.

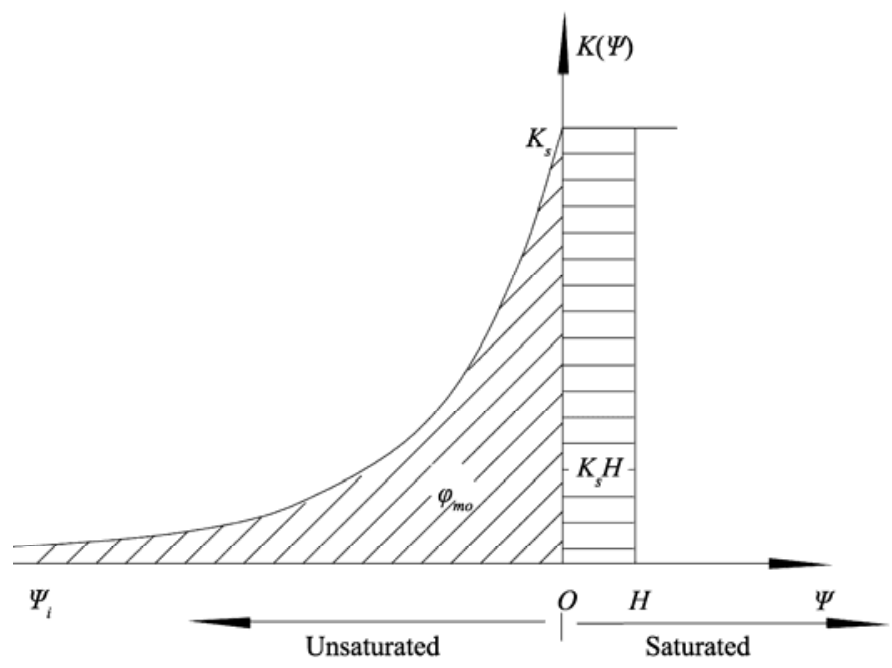

Fig. 1 Relationship between unsaturated permeability coefficient $(K(\Psi))$ and soil water pressure potential $(\Psi)$. $\Psi_{i}$ is the initial soil matric potential before infiltration, $\varphi_{m o}$ is the matric flux potential, $K_{s}$ is the saturated permeability coefficient, and $H$ is the infiltration head.

When $x=0$ (i.e., at the entry surface), the soil moisture flux $(q)$ is equal to the infiltration rate $(i)$, and thus:

$$
i=-\frac{\partial \varphi}{\partial x}
$$

For $\Psi=\Psi_{p}=H$, Equation 2 can be expressed as:

$$
\begin{gathered}
\varphi=\int_{\Psi_{i}}^{H} K(\Psi) d \Psi=\int_{\Psi_{i}}^{0} K(\Psi) d \Psi+\int_{0}^{H} K(\Psi) d \Psi . \\
\int_{0}^{H} K(\Psi) d \Psi=K_{s} H .
\end{gathered}
$$

Where, $H$ is the infiltration head $(\mathrm{cm})$ and $K_{s}$ is the saturated permeability coefficient $(\mathrm{cm} / \mathrm{min})$.

The matric flux potential, $\varphi_{m o}\left(\mathrm{~cm}^{2} / \mathrm{min}\right)$, is defined as (Gardner, 1958; Reynolds and Elrick, 1985):

$$
\varphi_{m o}=\int_{\Psi_{i}}^{0} K(\Psi) d \Psi
$$

Thus, $\varphi$ could be obtained by:

$$
\varphi=\varphi_{m o}+K_{s} H
$$

At the wetting front, i.e., $x=x_{f}\left(x_{f}\right.$ represents the wetting front distance $\left.(\mathrm{cm})\right)$, we could get: 


$$
\varphi=\int_{\Psi_{i}}^{\Psi_{i}} K(\Psi) d \Psi=0 .
$$

Then, the infiltration rate $(i)$ could be obtained by combining Equations 3, 7, and 8.

$$
i=-\frac{\left(\varphi_{m o}+K_{s} H\right)-0}{0-x_{f}}=\frac{\varphi_{m o}+K_{s} H}{x_{f}} .
$$

The cumulative horizontal infiltration $(I)$ is expressed as Equation 10.

$$
I=\left(\theta_{\text {mean }}-\theta_{i}\right) x_{f}=\Delta \theta x_{f} .
$$

Where, $\theta_{\text {mean }}$ is the average soil moisture content after infiltration in the entire wetted zone $\left(\mathrm{cm}^{3} / \mathrm{cm}^{3}\right), \theta_{i}$ the initial soil moisture content before infiltration $\left(\mathrm{cm}^{3} / \mathrm{cm}^{3}\right), \Delta \theta$ the difference between soil moisture content after infiltration in the entire wetted zone and initial soil moisture content before infiltration $\left(\mathrm{cm}^{3} / \mathrm{cm}^{3}\right)$. It should be noted that we assumed the soil moisture content after infiltration in the entire wetted zone as the average soil moisture content rather than the saturated soil moisture content (Green and Ampt, 1911).

By combining Equations 9 and 10, we could obtain the following equation:

$$
I i=\Delta \theta\left(\phi_{m o}+K_{s} H\right) .
$$

The Philip infiltration formula for the cumulative horizontal infiltration $(I)$ is expressed as follows (Philip, 1957a, b, 1969; Jury et al., 1991; Lal and Shukla, 2004).

$$
I=S_{H} t^{\frac{1}{2}} \text {. }
$$

Where, $t$ is the infiltration time ( $\min )$ and $S_{H}$ is the sorptivity at specific infiltration head $H$ $\left(\mathrm{cm} / \mathrm{min}^{0.5}\right)$.

For the infiltration rate $(i=d I / d t)$, by substituting Equation 12 into $i=d I / d t$, then we could obtained the following equation:

$$
i=\frac{1}{2} S_{H} t^{-\frac{1}{2}}
$$

By combining Equations 12 and 13, then we could get:

$$
I i=\frac{1}{2} S_{H}^{2} \text {. }
$$

Finally, the following equation could be obtained by combining Equations 11 and 14.

$$
\frac{S_{H}^{2}}{2 \Delta \theta}=\phi_{m o}+K_{s} H \text {. }
$$

From Equation 15, it can be seen that $S_{H}{ }^{2} /(2 \Delta \theta)$ and $H$ shows a linear relationship, and $\varphi_{m o}$ is the intercept and $K_{s}$ is the slope. So, $\varphi_{m o}$ and $K_{s}$ can be obtained using the regression analysis based on the one-dimensional horizontal infiltration experiments.

\subsection{Unsaturated permeability coefficient}

In Gardner model (Gardner, 1958), the unsaturated permeability coefficient $(K(\Psi))$ is represented by Equation 16:

$$
K(\Psi)=K_{s} \mathrm{e}^{\alpha \Psi}, \Psi<0 .
$$

Where, $\alpha$ is the pore size distribution parameter, which represents the reduction rate of soil permeability coefficient as $\Psi$ becomes more negative.

By substituting Equation 16 into Equation 6, then we could obtained the following equation:

$$
K_{s}-K_{i}=\alpha \varphi_{m o} \text {. }
$$

Where, $K_{i}$ is the permeability coefficient corresponding to the initial soil matric potential before infiltration $\left(\Psi_{i}\right)$. If the soil is initially drier, i.e., $K_{i}<<K_{s}$ (Scotter et al., 1982), thus Equation 17 can 
often be simplified as follows:

$$
K_{s}=\alpha \varphi_{m o} \text {. }
$$

Then, $\alpha$ in Equation 16 could be calculated by Equation 19 .

$$
\alpha=\frac{K_{s}}{\varphi_{m o}} .
$$

It should be emphasized that both the saturated permeability coefficient $\left(K_{s}\right)$ and the pore size distribution parameter $(\alpha)$ prescribed in the Gardner model (i.e., Eq. 16) are obtained using the one-D method and thus the unsaturated permeability coefficient $(K(\Psi))$ could be subsequently obtained using Gardner model (i.e., Eq. 16).

\section{Materials and methods}

\subsection{Study area}

Soil samples were collected from a corn field of Tajik Abati Town, Taxkorgan Tajik Autonomous County, Kashi Prefecture of Xinjiang, China. The town is located between $38^{\circ} 58^{\prime}-39^{\circ} 04^{\prime} \mathrm{N}$ and $77^{\circ} 14^{\prime}-77^{\circ} 19^{\prime} \mathrm{E}$ with an average elevation of $1178 \mathrm{~m}$ a.s.l. The region is characterized by a temperate continental arid climate with rather scarce precipitation $(\sim 50 \mathrm{~mm})$ and extremely high evaporation $(\sim 2500 \mathrm{~mm})$. The annual average temperature is $11.7^{\circ} \mathrm{C}$ with an extreme minimum temperature of $-24.4^{\circ} \mathrm{C}$ and an extreme maximum temperature of $49.1{ }^{\circ} \mathrm{C}$. The annual sunshine hours range from 2450 to $3000 \mathrm{~h}$ and the frostless period is $245 \mathrm{~d}$. Groundwater depth in the study area is shallow, varying from 0.2 to $1.4 \mathrm{~m}$. Soil physical properties are shown in Table 1.

Table 1 Soil physical properties at the depth of $0-60 \mathrm{~cm}$ in the study area

\begin{tabular}{ccccc}
\hline \multicolumn{3}{c}{ Proportion of soil particle size (weight; \%) } & Soil texture & $\begin{array}{c}\text { Dry bulk density } \\
\left(\mathrm{g} / \mathrm{cm}^{3}\right)\end{array}$ \\
\hline Sand $(2-0.05 \mathrm{~mm})$ & Silt $(0.05-0.002 \mathrm{~mm})$ & Clay $(<0.002 \mathrm{~mm})$ & & Loamy sand \\
\hline 72.96 & 24.67 & 2.37 & 1.48 \\
\hline
\end{tabular}

\subsection{Experimental device}

The experimental device included a marriotte bottle and a horizontal soil column. The marriotte bottle was $70 \mathrm{~cm}$ in the height and $5 \mathrm{~cm}$ in the inner diameter. The horizontal soil column collector, $80 \mathrm{~cm}$ in the length and $10 \mathrm{~cm}$ in the inner diameter, was made of a $0.5-\mathrm{cm}$ thick plexiglass cylinder (Fig. 2).

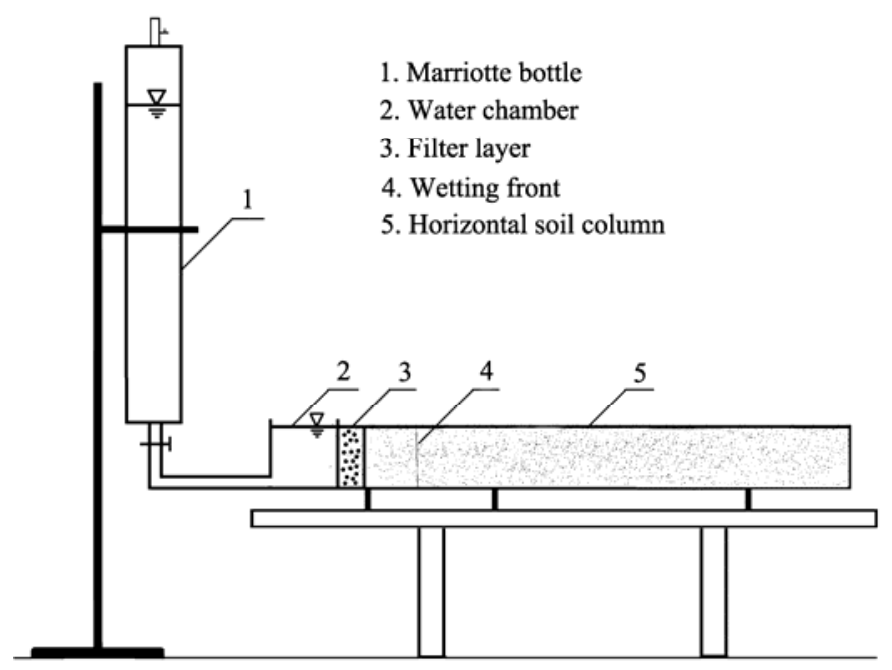

Fig. 2 Experimental device for water infiltration experiments of horizontal soil column 


\subsection{Experimental design}

The infiltration heads (corresponding to the center of horizontal soil column) were designed at 0 , $10,20,30,40,50,60$ and $70 \mathrm{~cm}$. Each experiment was repeated three times under the same infiltration head to ensure the data consistency.

\subsection{Experimental procedure}

The laboratory experiments were conducted during the period of 19 days from 16 October to 3 November (2012) at the Aksu National Field Scientific Observation and Research Station for Farmland Ecosystem $\left(40^{\circ} 37^{\prime} \mathrm{N}, 80^{\circ} 51^{\prime} \mathrm{E}\right)$, Xinjiang of China.

3.4.1 Filling of soil samples

Soil samples were taken from a corn field and three replicated sample plots $(0.6 \mathrm{~m} \times 1.0 \mathrm{~m} \times 1.5 \mathrm{~m}$ each) were designed along the diagonal of the field. Three soil samples ( $20 \mathrm{~kg}$ for each) were collected at the depth of 0-60 cm, and then mixed into one. In the laboratory, the samples were air dried, smashed and sieved to ensure the uniformity of initial soil moisture content and soil texture. The samples were then filled into a plexiglass cylinder at an interval of $3 \mathrm{~cm}$ depth and compacted during the filling to avoid possible unconformities of soil layers. The samples were placed for 24 $\mathrm{h}$ to achieve a uniform soil moisture content, and the initial soil moisture content was 0.02 $\mathrm{cm}^{3} / \mathrm{cm}^{3}$.

\subsubsection{Installation of experimental device}

After filling soil samples, we connected the water chamber and the plexiglass cylinder using screws, and smeared Vaseline on places where water may seep (such as the screws), ensuring that the horizontal soil column was water-tight.

A marriotte bottle was used to supply water for the horizontal soil column under a constant water head to ensure the soil to be saturated at the inlet side and also to avoid the gravity flow. At the same time, the water supply volume, namely the infiltration water added to the horizontal soil column, was determined.

3.4.3 Records of experimental data

The valve of the marriotte bottle was opened to supply water to the water chamber until the chamber was filled, then the vent valve of the water chamber was closed. Subsequently, we started the stopwatch and recorded the start time, infiltration time, liquid level of the marriotte bottle, and distances from the wetting front to the water source at different time intervals (i.e., 1, 2, 5 min, etc.).

\subsection{Data analysis}

In this study, all data were analyzed using Microsoft Excel and all figures were plotted using Microsoft Excel and Photoshop software package.

\section{Results}

\subsection{Relationships between the cumulative horizontal infiltration and the wetting front distance}

The relationships between the cumulative horizontal infiltration $(I)$ and the wetting front distance $\left(x_{f}\right)$ at different infiltration heads are shown in Figure 3. The linear relationships between the cumulative horizontal infiltration and the wetting front distance indicate that it is appropriate to assume that the soil moisture content after infiltration in the entire wetted zone equals to the average soil moisture content in the entire wetted zone. The slope of the line is the $\Delta \theta$, i.e., the difference between the average soil moisture content after infiltration in the entire wetted zone and the initial soil moisture content before infiltration, and $\Delta \theta$ values corresponding to different infiltration heads are shown in Table 2.

\subsection{Relationships between the cumulative horizontal infiltration and the square root of infiltration time}

The relationships between the cumulative horizontal infiltration $(I)$ and the square root of 
infiltration time $\left(t^{0.5}\right)$ are shown in Figure 4. The linear relationships between the cumulative horizontal infiltration and the square root of infiltration time indicate that the Philip infiltration formula can better reflect the characteristics of cumulative horizontal infiltration at different infiltration heads. The slope of the line is the sorptivity $\left(S_{H}\right)$, and $S_{H}$ values corresponding to different infiltration heads are shown in Table 2.

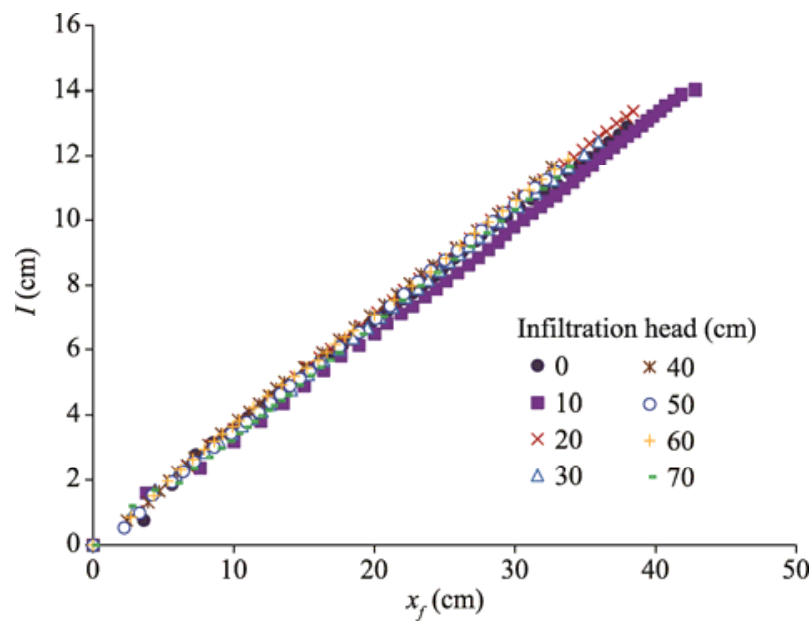

Fig. 3 Relationships between the cumulative horizontal infiltration $(I)$ and the wetting front distance $\left(x_{f}\right)$ at different infiltration heads

Table 2 Results for horizontal infiltration experiments corresponding to different infiltration heads

\begin{tabular}{cccc}
\hline$H(\mathrm{~cm})$ & $\Delta \theta\left(\mathrm{m}^{3} / \mathrm{m}^{3}\right)$ & $S_{H}\left(\mathrm{~cm} / \mathrm{min}^{0.5}\right)$ & $S_{H}{ }^{2} /(2 \Delta \theta)\left(\mathrm{cm}^{2} / \mathrm{min}^{2}\right)$ \\
\hline 0 & 0.36 & 0.9153 & 1.1895 \\
10 & 0.33 & 0.9194 & 1.2850 \\
20 & 0.35 & 1.0449 & 1.5531 \\
30 & 0.34 & 0.9438 & 1.2921 \\
40 & 0.37 & 1.0568 & 1.5262 \\
50 & 0.35 & 1.0814 & 1.6725 \\
60 & 0.36 & 1.1927 & 2.0064 \\
70 & 0.33 & 1.1509 & 2.0202 \\
\hline
\end{tabular}

Note: $H$ is the infiltration head; $\Delta \theta$ is the difference between the average soil moisture content after infiltration in the entire wetted zone and the initial soil moisture content before infiltration; $S_{H}$ is the sorptivity at specific infiltration head $H$; and $S_{H}^{2} /(2 \Delta \theta)$ is a statistic.

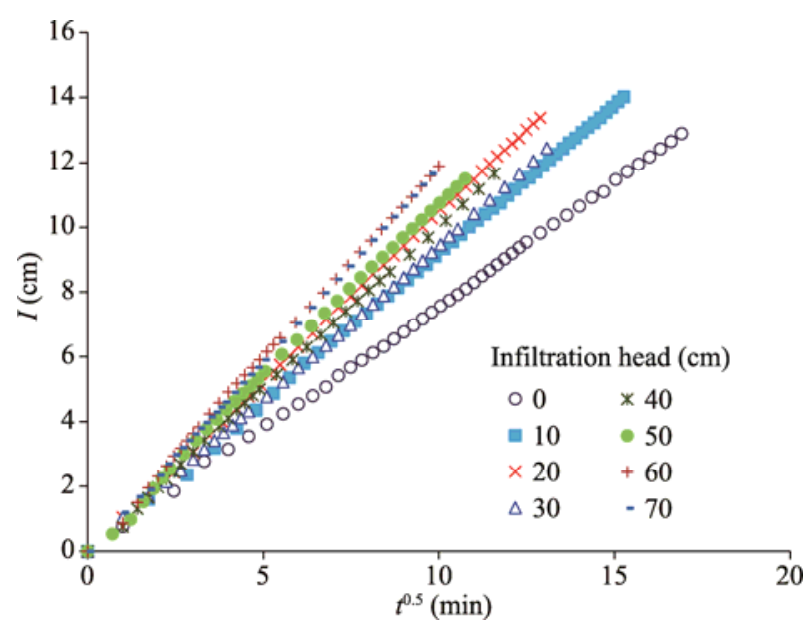

Fig. 4 Relationships between the cumulative horizontal infiltration $(I)$ and the square root of infiltration time $\left(t^{0.5}\right)$ at different infiltration heads 


\subsection{Saturated permeability coefficient $\left(K_{s}\right)$ and pore size distribution parameter $(\alpha)$}

The values of statistic parameter $S_{H}{ }^{2} /(2 \Delta \theta)$ corresponding to different infiltration heads $(H)$ were calculated using the experimental data and the relationship between $S_{H}{ }^{2} /(2 \Delta \theta)$ and $H$ is shown in Figure 5. Although only 8 data points, the linear relationship between $S_{H}{ }^{2} /(2 \Delta \theta)$ and $H$ is relatively robust with $R^{2}=0.8419$, meaning that the theoretical expression of Equation 15 is acceptable. In Figure 5, the slope of the linear regression equation is the saturated permeability coefficient $\left(K_{s}\right)$ and the intercept is the matric flux potential $\left(\varphi_{m o}\right)$. Thus, $K_{s}$ and $\varphi_{m o}$ values can be obtained from Figure 5: $K_{s}=0.0119 \mathrm{~cm} / \mathrm{min}$ (or $K_{s}=171.36 \mathrm{~mm} / \mathrm{d}$ ), and $\varphi_{m o}=1.1509 \mathrm{~cm}^{2} / \mathrm{min}$. Consequently, the pore size distribution parameter $\alpha=1.03 / \mathrm{m}$ (see Eq. 19).

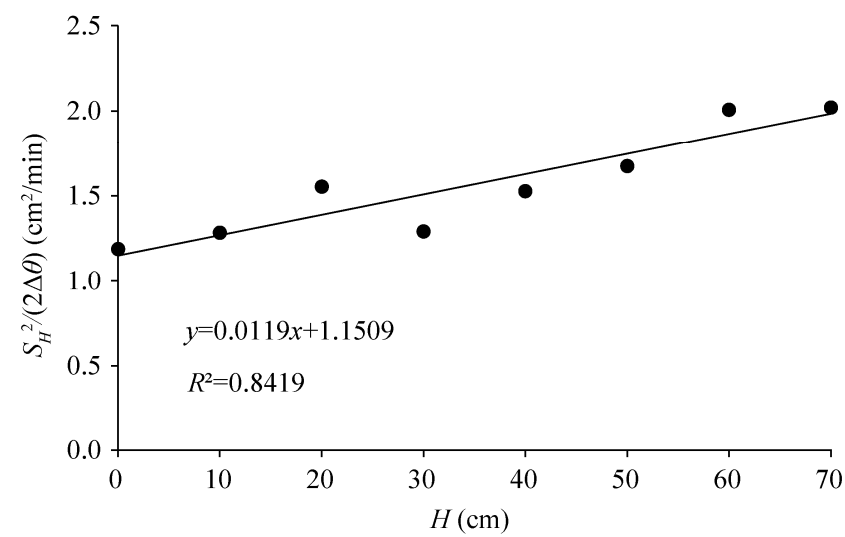

Fig. 5 Relationship between $S_{H}{ }^{2} /(2 \Delta \theta)$ and infiltration head $(H) . S_{H}$ is the sorptivity at specific infiltration head $H ; \Delta \theta$ is the difference between the average soil moisture content after infiltration in the entire wetted zone and the initial soil moisture content before infiltration.

\section{Discussion}

The Green-Ampt model (Green and Ampt, 1911) assumed that the soil moisture content after infiltration in the entire wetted zone was the saturated soil moisture content $\left(\theta_{\mathrm{s}}\right)$ and that $\Delta \theta$ was the difference between the saturated soil moisture content after infiltration $\left(\theta_{\mathrm{s}}\right)$ and the initial soil moisture content before infiltration $\left(\theta_{i}\right)$, i.e., $\Delta \theta=\theta_{s}-\theta_{i}$. However, in the laboratory experimental case, the soil moisture is unevenly distributed after infiltration and is difficulty to reach saturation in the entire wetted zone. Thus, the assumption that soil moisture content after infiltration in the entire wetted zone is uniform and equals to the saturated soil moisture content does not reflect the reality. Consequently, we assumed the soil moisture content after infiltration in the entire wetted zone as the average soil moisture content rather than the saturated soil moisture content (see Eq. 10). This study demonstrated a strong linear relationship between the cumulative horizontal infiltration and the wetting front distance, and the linear relationship suggests that it is reasonable to assume that the soil moisture content after infiltration equals to the average soil moisture content in the entire wetted zone. Therefore, it is appropriate to take the $\Delta \theta$ as the average increments of soil moisture content in the entire wetted zone. That is, $\Delta \theta=\theta_{\text {mean }}-\theta_{i}$, which can be easily calculated from the wetting front distance and infiltration water volume.

The saturated permeability coefficient $\left(K_{s}\right)$ prescribed in the Gardner model (i.e., Eq. 16) determined using the one-D method in this study was $171.36 \mathrm{~mm} / \mathrm{d}$ for loamy sand, being rather similar with that $(165.00 \mathrm{~mm} / \mathrm{d})$ determined using the constant head method (Jury et al., 1991; Hillel, 1998). The similarity indicates that it is quite feasible to use the one-D method for determining the saturated permeability coefficient of loamy sand.

The pore size distribution parameter $(\alpha)$, a key parameter in determining the unsaturated permeability coefficient (see Eq. 16), was obtained under the assumption that the initial soil moisture content before infiltration $\left(\theta_{i}\right)$ is low and the permeability coefficient corresponding to the initial soil matric potential before infiltration $\left(K_{i}\right)$ is far less than the saturated permeability 
coefficient $\left(K_{s}\right)$. Hence, the smaller the initial soil moisture content before infiltration during the one-dimensional horizontal infiltration experiments, the better the experimental result is. The pore size distribution parameter $(\alpha)$ prescribed in the Gardner model (Gardner, 1958) obtained using the one-D method in this study was about $1.03 / \mathrm{m}$ for loamy sand, being approximately in agreement with the value obtained by Elrick et al. (1989).

It should be reiterated that both the saturated permeability coefficient $\left(K_{s}\right)$ and the pore size distribution parameter $(\alpha)$ prescribed in the Gardner model (i.e., Eq. 16) were obtained from the one-D method and thus the unsaturated permeability coefficient $(K(\Psi))$ could be subsequently obtained using Gardner model (i.e., Eq. 16). To further assess the acceptability and applicability of the one-D method in determining the unsaturated permeability coefficient, we analyzed the relationships between unsaturated permeability coefficient and soil water suction calculated using Gardner model based on the one-D method and using van Genuchten model (van Genuchten, 1980). The van Genuchten model is a widely-used model in determining the unsaturated permeability coefficient. The basic equations of van Genuchten model are as follows:

$$
\begin{gathered}
\theta=\theta_{r}+\frac{\theta_{s}-\theta_{r}}{\left[1+(\sigma S)^{n}\right]^{m}} . \\
K(S)=\frac{K_{s}\left\{1-(\sigma S)^{n-1}\left[1+(\sigma S)^{n}\right]^{-m}\right\}^{2}}{\left[1+(\sigma S)^{n}\right]^{m+1}} . \\
m=1-\frac{1}{n}(0<m<1, n>1) .
\end{gathered}
$$

Where, $K(S)$ is the unsaturated permeability coefficient $(\mathrm{mm} / \mathrm{d}) ; K_{s}$ is the saturated permeability coefficient $(\mathrm{mm} / \mathrm{d}) ; \theta$ is the volumetric soil moisture content $\left(\mathrm{cm}^{3} / \mathrm{cm}^{3}\right) ; \theta_{r}$ is the residual soil moisture content $\left(\mathrm{cm}^{3} / \mathrm{cm}^{3}\right) ; \theta_{s}$ is the saturated soil moisture content $\left(\mathrm{cm}^{3} / \mathrm{cm}^{3}\right) ; S$ is the soil water suction $(\mathrm{cm})$, also namely the soil water pressure potential; and $\sigma, n$ and $m$ are the undetermined parameters affecting the shape of soil-water characteristic curve.

The relationships between unsaturated permeability coefficient and soil water suction for loamy sand calculated using Gardner model based on the one-D method and using van Genuchten model are shown in Figure 6. The excellent agreement between the two curves indicates that it is feasible to use the one-D method for determining the unsaturated permeability coefficient of loamy sand.

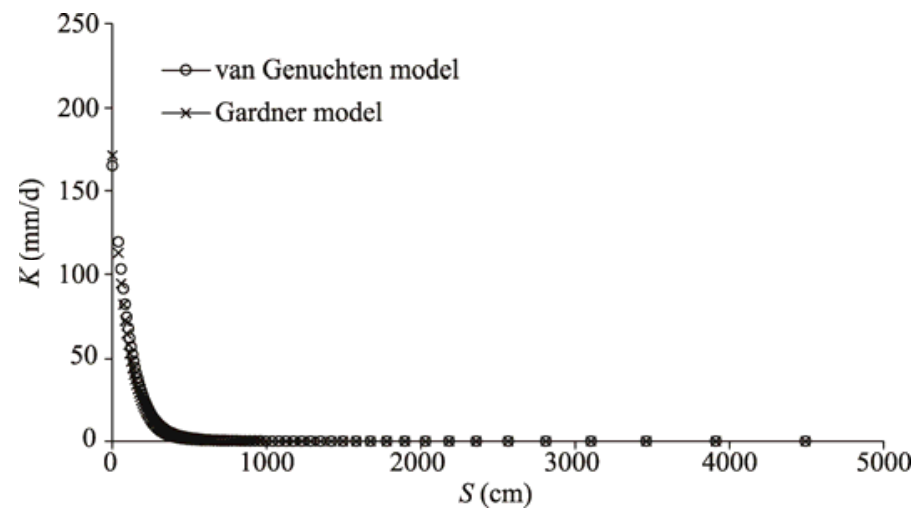

Fig. 6 Relationships between unsaturated permeability coefficient $(K)$ and soil water suction $(S)$ calculated using Gardner model based on the one-D method (one-dimension horizontal infiltration method) and using van Genuchten model

The instantaneous profile method is another widely-used approach for determining the unsaturated permeability coefficient of homogeneous or nonhomogeneous soils under the condition that soil moisture content is not affected by groundwater (Watson, 1966; Askarinejad et al., 2012), but it is time-consuming and error-prone because the dynamics of soil water suction 
and soil moisture content are normally hard to determine (Baker et al., 1974). By contrast, in the one-dimensional horizontal infiltration experiments, the needed parameters (including the cumulative horizontal infiltration, the wetting front distance and the infiltration time) can be readily determined and the experimental process is relatively easy and less time-consuming.

\section{Conclusions}

This study evaluated the acceptability and applicability of the one-dimensional horizontal infiltration method (one-D method) proposed by Yang and Lei (1991) for simultaneously determining the saturated and unsaturated permeability coefficients of loamy sand. The saturated permeability coefficient and the pore size distribution parameter prescribed in the Gardner model for loamy sand were determined using the one-D method and the unsaturated permeability coefficient $(K(\Psi))$ was subsequently obtained using Gardner model. The saturated permeability coefficient obtained from the one-D method agreed well with that from the constant head method, and the relationship between unsaturated permeability coefficient and soil water suction calculated using Gardner model based on the one-D method was also in good agreement with that obtained using van Genuchten model. The fact that the determination of saturated and unsaturated permeability coefficients of loamy sand can be accomplished only in few days using the one-D method with very simple equipment (i.e., a set of horizontal infiltration device) also means that the one-D method is applicable.

\section{Acknowledgements}

This study was funded by the National Basic Research Program of China (2013CB429902) and the National Natural Science Foundation of China (U1303181, 41671032).

\section{References}

Ankeny M D, Ahmed M, Kaspar T C, et al. 1991. Simple field method for determining unsaturated hydraulic conductivity. Soil Science Society of America Journal, 55(2): 467-470.

Askarinejad A, Beck A, Casini F, et al. 2012. Unsaturated hydraulic conductivity of a silty sand with the instantaneous profile method. In: Mancuso C, Jommi C, D’Onza F. Unsaturated Soils: Research and Applications. Berlin: Springer, 215-220.

Baker F G, Veneman P L M, Bouma J. 1974. Limitations of the instantaneous profile method for field measurement of unsaturated hydraulic conductivity. Soil Science Society of America Journal, 38(6): 885-888.

Daliri F. 2011. A review of theoretical and experimental methods to measure coefficient of permeability of unsaturated soils. Electronic Journal of Geotechnical Engineering, 16: 1665-1677.

Elrick D E, Reynolds W D, Tan K A. 1989. Hydraulic conductivity measurements in the unsaturated zone using improved well analyses. Ground Water Monitoring \& Remediation, 9(3): 184-193.

Elrick D E, Reynolds W D. 1992. Methods for analyzing constant-head well permeameter data. Soil Science Society of America Journal, 56(1): 320-323.

Fredlund D G, Rahardjo H. 1993. Soil Mechanics for Unsaturated Soils. New York: John Wiley \& Sons Inc., 147-163.

Ganjidoost H, Mousavi J S, Soroush A. 2015. Adaptive network-based fuzzy inference systems coupled with genetic algorithms for predicting soil permeability coefficient. Neural Processing Letters, 44(1): 53-79.

Gardner W R. 1958. Some steady-state solutions of the unsaturated moisture flow equation with application to evaporation from a water table. Soil Science, 85(4): 228-232.

Green W H, Ampt G A. 1911. Studies on soil physics: I. Flow of air and water through soils. The Journal of Agricultural Science, 4(1): 1-24.

Hillel D. 1998. Environmental Soil Physics. San Diego: Academic Press, 173-201.

Houseworth J E, Leem J. 2009. A quasilinear model for solute transport under unsaturated flow. Vadose Zone Journal, 8(4): 1031-1037.

Jury W A, Gardner W R, Gardner W H. 1991. Soil Physics (5 ${ }^{\text {th }}$ ed.). New York: Wiley Publishers, 134-135.

Klute A. 1952. A numerical method for solving the flow equation for water in unsaturated materials. Soil Science, 73(2): 105-116.

Klute A, Dirksen. 1986. Hydraulic conductivity and diffusivity: Laboratory methods. In: Klute A. Methods of Soil Analysis, 
Part 1. Madison: Soil Science Society of America Inc., 687-734.

Lal R, Shukla M K. 2004. Principles of Soil Physics. New York: Marcel Dekker, 362-373.

Lu N, Likos W J. 2012. Unsaturated Soil Mechanics. Hoboken: John Wiley \& Sons, 337-358.

Philip J R. 1957a. The theory of infiltration: 1. The infiltration equation and its solution. Soil Science, 83(5): 345-358.

Philip J R. 1957b. The theory of infiltration: 4. Sorptivity and algebraic infiltration equations. Soil Science, 84(3): $257-264$.

Philip J R. 1969. Theory of infiltration. Advances in Hydroscience, 5: 215-296.

Philip J R, Knight J H, Waechter R T. 1989. Unsaturated seepage and subterranean holes: Conspectus, and exclusion problem for circular cylindrical cavities. Water Resources Research, 25(1): 16-28.

Radcliffe D E, Rasmussen T C. 2002. Soil water movement. In: Warrick A W. Soil Physics Companion. Boca Raton: CRC Press, 85-126.

Reynolds W D, Elrick D E. 1985. In situ measurement of field-saturated hydraulic conductivity, sorptivity, and the $\alpha$-parameter using the Guelph permeameter. Soil Science, 140(4): 292-302.

Scherer T F, Seelig B, Franzen D. 1996. Soil, water and plant characteristics important to irrigation. In: North Dakota State University (NDSU) Extension Bulletin EB-66. Fargo: North Dakota State University.

Schiff L, Dreibelbis F R. 1949. Preliminary studies on soil permeability and its application. Eos, Transactions American Geophysical Union, 30(5): 759-766.

Scotter D R, Clothier B E, Harper E R. 1982. Measuring saturated hydraulic conductivity and sorptivity using twin rings. Australian Journal of Soil Research, 20(4): 295-304.

Shabani A, Sepaskhah A R. 2009. Determination of minimum soil clolmn length to determing soul hydraulic diffusivity function through a sample method. Iranian Journal of Soil and Water Research, 40(1): 35-42.

Shao M A, Horton R. 1998. Integral method for estimating soil hydraulic properties. Soil Science Society of America Journal, 62(3): 585-592.

Su P X. 2000. Research on soil dynamic constants of sandy land. Journal of Desert Research, 20(3): 329-332. (in Chinese)

van Genuchten M T. 1980. A closed-form equation for predicting the hydraulic conductivity of unsaturated soils. Soil Science Society of America Journal, 44(5): 892-898.

Wang Q, Tong L Y. 2014. Determination permeability coefficient from piezocone. Advances in Materials Science and Engineering, 2014: 396428, doi: 10.1155/2014/396428.

Wang Q J, Horton R, Shao M A. 2002. Horizontal infiltration method for determining Brooks-Corey model parameters. Soil Science Society of America Journal, 66(6): 1733-1739.

Wang W Y, Zhang J F. 1990. Simultaneous determination of water movement parameters of unsaturated soil in a horizontal soil column. Journal of Hydraulic Engineering, (7): 26-30. (in Chinese)

Watson K K. 1966. An instantaneous profile method for determining the hydraulic conductivity of unsaturated porous materials. Water Resources Research, 2(4): 709-715.

Yang S X, Lei Z D. 1991. Hydraulic conductivity determination using horizontal column infiltration. Journal of Hydraulic Engineering, (5): 1-7. (in Chinese)

Zhang Z Y, Sa T T, Tie X Q, et al. 2013. Soil water infiltration and its affecting factors. Applied Mechanics and Materials, 353-356: 2983-2986. 